Conclusions The distribution of RTI death varies across different economic categories and regions of the world by road user type.

\section{FACTORS ASSOCIATED WITH CYBERBULLY VICTIMISATION AMONG SECONDARY SCHOOL ADOLESCENTS IN OYO STATE, NIGERIA}

Adesola Olumide, Emmanuel Adebayo. University of Ibadan, Nigeria

\subsection{6/injuryprev-2016-042156.924}

Background Cyberbullying, described as, “a form of aggression involving the use of information and communication technology to post or send harassing or embarrassing messages to another person", is an emerging global problem. This study presents findings on the prevalence and factors associated with cyberbully victimisation among secondary school adolescents in Oyo state, Nigeria.

Methods A cross-sectional study that utilised a multi-stage sampling technique to select 653 students from schools within the state was conducted. Information on students' socio-demographic characteristics and history of cyberbullying in the three-month preceding the study was obtained from the students.

Results The respondents' mean age was $14.2 \pm 2.2$ years and $51.3 \%$ were females. About $50.7 \%$ of all respondents were in senior secondary classes and $50.5 \%$ had internet access. Two hundred and sixty (39.8\%) had been victims of cyberbullying and 94.3\% experienced cyberbullying after school hours. Respondents were often harassed through phone calls (53.2\%), in chat rooms $(25.2 \%)$ and through websites (0.4\%). Fifty-two percent of victims reported the incident. Of these $52.7 \%$ informed a friend, $28.7 \%$ informed a parent/guardian and $1.6 \%$ their class teacher. Factors associated with cyberbully victimisation were the respondents' gender (females more than males), older age, access to internet and being in a senior class. Multiple logistic regression analysis revealed that students with internet access had a higher odds of being victims of cyberbullying $(\mathrm{OR}=2.5, \mathrm{CI}$ : $=1.7-$ 3.6). Respondents in senior classes also had a higher odds of being victims of cyberbullying $(\mathrm{OR}=1.7, \mathrm{CI}:=1.1-2.6)$.

Conclusions The prevalence of cyberbully victimisation was high and students with internet access and those in senior classes were more likely to be victims. Interventions to prevent cyberbullying and improve reporting by victims need to be instituted in schools in the study area in order to curb the problem.

\section{SAFETY OF BABIES, CHILDREN AND YOUTH}

Gregoria Paixão Von Amann, Ines Silva, Joana Azevedo. Directorate General of Health, Ministry of Health; , MAPFRE Foundation, DOREL Industries, Sandra Nascimento, Portuguese Association for Child Safety Promotion, Portugal

\subsection{6/injuryprev-2016-042156.925}

Background Despite the large reduction of child mortality due to traffic collisions, safe and secure transportation of children from birth and through the life cycle, it continues being a concern of the Ministry of Health and the Ministry of Internal Affairs. For this common problem they join effort and under the auspicious of the Decade of Action of Road Safety, on 11 may 2011 launched a project aimed to improve safe transport of newborns since they leave Hospital maternity and along childhood.

Methods The National Road Safety Strategy reinforce strategic and operational objectives and the National Program of Injury
Prevention develops a project called Safety of Babies, Children and Youth targets of reducing child mortality and serious injury and to increase the use of child restraint systems.

For the implementation of the project we have a partnership with DOREL, a company that produces in Portugal child restraint systems and MAPFRE Foundation who developed a website on child road safety supports costs from training health professional and production of booklets and leaflets. The Portuguese Association for Child Safety Promotion, an NGO working in child safety give us their expertise in child restrains system and is also a partner of the project.

Results Currently we have 47 projects implemented in Hospital Maternity and Health Centres across the country, 6000 health professional involved and 60000 parents trained on how to use and use properly child restraints system. In the near future we will start working with the grandparents.

Conclusions The successful implementation of the project in the health services mobilised other actors that spontaneously joined us and are already engaged in community important aspects like control of the use of safety devices near schools and kindergartens by police forces and it's beginning a taxi drivers movement called 'taxis children's friends'.

\section{SCHOOL TRAVEL MODE OF CHILDREN IN URBAN LOW INCOME CITY, KARACHI, PAKISTAN}

1,2Uzma Rahim Khan, 2,3Junaid Abdul Razzak, 'Marie Hasselberg, 1,4Lucie Laflamme. ${ }^{1}$ Karolinska Institute, Sweden; ${ }^{2}$ Aga Khan University, Pakistan; ${ }^{3}$ Johns Hopkins University School of Medicine, Maryland; ${ }^{4}$ University of South Africa, South Africa

\subsection{6/injuryprev-2016-042156.926}

Background Children are more likely to be accompanied by the age 10 after which their independent mobility increases initially as pedestrian and bicyclists, and later as drivers of motorcycles and four-wheelers. The mobility patterns of children were mostly surveyed in high or upper middle income countries. The aim of this study was to understand the mobility in children to and from school in urban dense lower middle income country.

Methods This survey of school children was conducted from September to December 2014 in Karachi, Pakistan. Children in grades $6-10$ approximately age $10-14$ years from a random sample of 58 schools were interviewed face to face and their parents were interviewed on telephones. Mobility pattern was compared across gender.

Results There were 1288 children and 732 parents interviewed. On the day of survey, majority of children reported walking $(72 \%)$ to schools $(58.6 \%$ girls' vs $41.4 \%$ boys). Majority of parents $(71 \%)$ also reported walking as the travel model of children to and from school. There were $22 \%$ boys who came to school on their own compared to $16 \%$ girls however more girls $(30 \%)$ were accompanied with someone compared to boys (5.4\%). While according to parents $49 \%$ of boy children and $29 \%$ of girl children were allowed to go school on their own. Less than half $(43 \%)$ of children were allowed to cross main roads (same ratio of boys and girls). There were three-fourth girls who thought their parents never trust them when they were in road traffic on their own.

Conclusions Although walking is the common travel mode of both boys and girls for their schools but parents' license for mobility varies by sex of the children with more restrictions for girls. 